\section{Absetzbare Verwaltungskosten}

Für die Vermögensverwaltung erheben Banken unterschiedlich hohe Gebühren. Neben einer Mindestgebühr fallen meist Kosten je nach Beratungsaufwand und vorgenommenen Umschichtungen im Depot an. Bei der apoBank liegen die Kosten bei 1,34\% des verwalteten Vermögens pro Jahr zuzüglich $19 \%$ Mehrwertsteuer. „Die Hälfte der Verwaltungskosten ist steuerlich absetzbar, soweit die Provisionspauschale nicht $50 \%$ des Gesamthonorars übersteigt", erklärt Rene Hermanns, Gruppenleiter Portfolio Management.

Beim Vergleich der Konditionen sollten Anleger darauf achten, welche Leistungen in den Gebühren enthalten sind, rät Dieter Thomaschowski, Geschäftsführer des Analysehauses Investment Research in Change. „Wirbt eine Bank mit niedrigen Mindestgebühren, stellt dann aber jede telefonische Beratung in Rechnung, kann dies teurer kommen, als wenn alle Gespräche bereits in der Grundgebühr enthalten sind." Zudem sollten Ärzte nicht nur auf die Gebühren, sondern auch auf die erzielte Rendite achten.

\section{Aktien und Anleihen im Wechsel}

Bei der Vermögensverwaltung überlassen Ärzte Profis die Entscheidung, in welche Aktien und Anleihen konkret investiert wird. Die Anleger legen jedoch selbst die Aktien- und die Rentenquote fest. Als Faustregel gilt, dass Anleger in jungen Jahren v.a. auf Aktien setzen sollten., ,Sie bieten im historischen Vergleich ein höheres Renditepotenzial, haben durch ihre Kursschwankungen aber auch ein stärkeres Risiko“, so Rene Hermanns, Gruppenleiter Portfoliomanagement bei der apoBank. Nach einer Untersuchung der Bank konnten Anleger mit Aktien seit 1975 im Schnitt eine Rendite von über $11 \%$ pro Jahr erzielen. Der Jahresertrag von Rentenpapieren lag bei knapp $6 \%$.

Allerdings können Aktien bei Kurseinbrüchen auch zu vorübergehenden Verlustbringern werden. Das zeigt eine Studie des Fondsverbands BVI. Anleger, die während des Börsenbooms im Jahr 2000 auf deutsche Aktienfonds setzten, wären danach durch die beiden Kapitalmarkteinbrüche 2001 und 2008 derzeit 19,5\% im Minus. Mit europäischen Rentenfonds hätten Anleger hingegen im selben Zeitraum ein Plus von $52 \%$ erzielt. Ärzte sollten daher mit fortschreitendem Alter immer stärker in Anleihen umschichten, rät Hermanns.

\title{
Vermögensverwaltung
}

\section{Geldanlage mit Unterstützung vom Profi}

\author{
Wer seine Geldanlage in die Hand von Vermögensverwaltern \\ legt, kann profitieren. Wichtig ist, dass die Strategie gemeinsam \\ festgelegt wird - den Rest übernimmt dann der Experte.
}

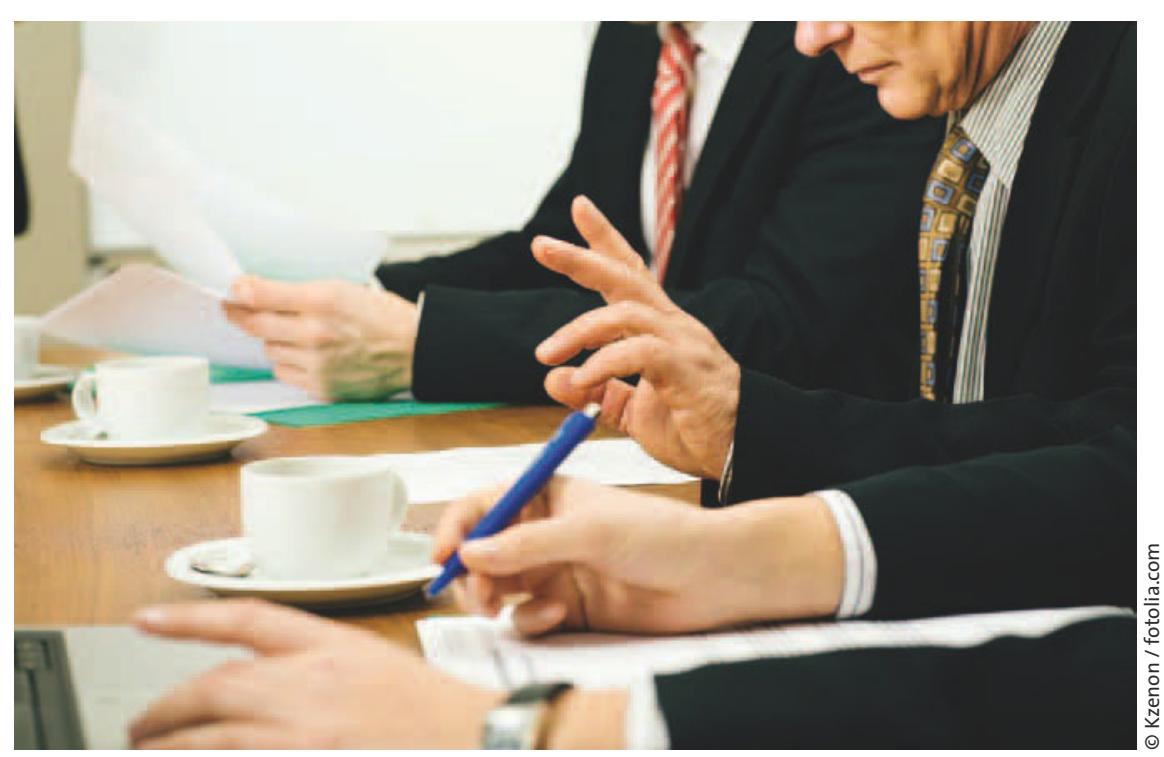

Ein ausführliches Gespräch über die Anlagestrategie ist der Grundstein für Vermögensverwalter.

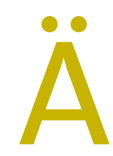

rzte sind im Beruf stark gefordert. Deshalb haben viele nur wenig Zeit, sich um ihre Kapitalanlagen zu kümmern. Immer mehr Anleger, auch Ärzte, bauen deshalb auf die professionelle Vermögensverwaltung, zum Beispiel auf darauf spezialisierte Banken.

„Bei der Vermögensverwaltung suchen erfahrene Experten an allen Aktien-und Anleihenmärkten der Welt nach Investmentprodukten, die das stärkste Gewinnpotenzial verbunden mit den geringsten Risiken bieten“, erklärt Jürgen Wirtz, Abteilungsleiter Vermögensverwaltung bei der Deutschen Apotheker- und Ärztebank, der Standesbank der Heilberufler (apoBank).
Kunden bestimmen den Portfoliomix mit

In einem ausführlichen Beratungsgespräch legen die Anleger selbst fest, wie viel Prozent ihres Geldes in sichere Staatsanleihen - im Fachjargon „Renten“ genannt - investiert werden, und wie viel Kapital in Aktien fließt, die deutlich höhere Ertragschancen bieten, deren Börsenkurse aber auch kräftig schwanken können. „Die Anlageentscheidungen werden nach dem persönlichen Renditeziel und der individuellen Risikoneigung der Kunden getroffen. Jede Aktien-/Rentengewichtung ist möglich“, erläutert Wirtz. Besonders sicherheitsbewusste Ärzte könnten zum Beispiel eine hundertprozentige Rentenstrategie wählen. Wirtz 